\title{
Risk Equalisation in Ireland and Australia: A Simulation Analysis to Compare Outcomes
}

\author{
John Armstrong a and Francesco Paolucci ${ }^{\mathrm{b}}$ \\ anstitute of Public Administration, Lansdowne Road, Dublin 4, Ireland. \\ E-mail: johnarmstrong@eircom.net \\ ${ }^{\mathrm{b}}$ Australian Centre for Economic Research on Health, Australian National University, Canberra, Australia.
}

Risk equalisation has been implemented in a number of countries as a means of providing explicit risk-adjusted transfers between health insurance undertakings to improve efficiency within the health insurance market, and make health insurance affordable. Two such countries are Australia and Ireland. In this article, a simulation exercise is carried out to compare the effectiveness of the two countries' risk equalisation schemes in meeting the policy objectives of encouraging insurers to be efficient and discouraging them from engaging in risk selection. The results of the analysis show that the Australian scheme is less effective than the Irish scheme in reducing the incentive for risk selection and in encouraging insurers to be efficient. The results provide evidence that direct standardisation mechanisms (as used in Ireland) can lead to superior outcomes as compared to indirect standardisation mechanisms (as used in Australia) in terms of promoting efficiency and deterring risk selection.

The Geneva Papers (2010) 35, 521-538. doi:10.1057/gpp.2010.23

Keywords: risk equalisation; risk selection; community rating; direct and indirect standardisation

\section{Introduction}

\section{Overview}

Many countries have introduced managed competition in health insurance to meet their public policy objectives in relation to the financing of health care, such as to achieve risk solidarity while promoting efficiency. ${ }^{1}$ Risk equalisation has long been considered to be an appropriate policy tool to meet these policy goals in many countries, particularly in those countries with a universal mandatory health insurance market. ${ }^{2}$ However, a growing number of countries with voluntary insurance markets have implemented or have been considering the introduction of cross-subsidies (e.g. risk equalisation) or subsidies (e.g. taxation) or a combination

\footnotetext{
${ }^{1}$ Enthoven (1978).

${ }^{2}$ Van de Ven et al. (2003, 2007).
} 
of both to achieve some degree of risk solidarity. ${ }^{3}$ Ireland and Australia represent two of these countries.

It should be noted, at the outset, that both countries are at significantly different stages in implementing risk equalisation. Australia has long had a system of transfers between insurers. In Ireland such a system has been proposed in legislation since 1994 and two different risk equalisation systems were introduced in 1996 and 2003, but no transfers occurred under them. ${ }^{4}$

The purpose of this article is to compare the effectiveness of risk equalisation in Australia and Ireland in achieving its policy goals of discouraging selection and of encouraging efficiency in the funding of health care. ${ }^{5}$ It does so by considering the size of the transfers between insurers under the two countries' risk equalisation schemes. In particular, the following question is addressed:

How, and to what extent, is risk equalisation, in Australia and Ireland, effective in deterring incentives for risk selection and in encouraging efficiency?

We seek to investigate these issues on an empirical basis through undertaking a simulation exercise to compare the size of transfers under the current Australian risk equalisation system and the 2003 Irish risk equalisation system.

\section{Outline of article}

The article is organised as follows. The first section presents a brief overview of the design of health care financing and insurance arrangements in the two countries. The similarities between the two countries' health care financing and insurance arrangements are a crucial precondition to carry out the empirical analysis (i.e. to use Irish data in the simulations on the Australian risk equalisation scheme). The subsequent section considers the role of risk equalisation in each of the countries and sets out the basic framework of risk equalisation in each of these countries. The section after that presents the model used in this article to evaluate each of the systems, while the penultimate section presents some of the results from our analysis. Finally, in the last section a discussion is presented of the results of the model and some tentative policy conclusions are outlined resulting directly from our analysis.

A glossary with a common terminology similar to that used before in previous literature in this area is provided in Appendix. ${ }^{6}$

\footnotetext{
${ }^{3}$ Paolucci et al. (2007), Armstrong (2008).

${ }^{4}$ Transfers have been made through the tax system between younger and older people in a system that has all the characteristics of a risk equalisation but is not referred to as such within Ireland (Armstrong, 2010).

${ }^{5}$ See glossary and for fuller explanations Schut (1995) and van Barneveld et al. (2001).

${ }^{6}$ In this regard we, where possible, replicate the definitions set out by Armstrong et al. (2010) and van de Ven et al. (2003).
} 


\section{Background}

Overview of health care financing and delivery in both countries

Both countries have remarkable similarities in terms of the financing and delivery of services within their health system. ${ }^{7,8,9}$ In this section, we provide a brief overview of the main features of health care financing arrangements in both countries.

\section{Universal coverage}

In Ireland, residents of the European Union have an entitlement to public hospital care, delivered and financed by the State. In addition, subsidy payments are made for certain medically prescribed drug costs above a monthly threshold. Thus, an element of universality exists within the system in terms of access to services. In Australia, under the Medicare system, entitlement to free public hospital care (in a public bed) is provided to Australian residents. In addition, certain other services are provided on a subsidised basis.

\section{Health funding}

In both countries funding for the system is made through a combination of tax, private insurance and out-of-pocket expenditures. While the absolute size of each of these components is somewhat different given the relative size of the countries, the relative sizes in monetary terms of each of these sources of funding are similar for both countries. For example, in both countries voluntary health insurance makes up no more than 15 per cent of total expenditure on health care. ${ }^{10}$

\section{Public/private mix}

A key element of commonality between the two systems is the significant mix of both the public and private sectors in terms of the delivering and funding services within the system. This feature occurs in a number of ways that are salient for our analysis. First, services are delivered by the State in public hospitals. Allied to this, a significant proportion of those receiving treatment in public hospitals have private health insurance. Second, the State provides some services within public hospitals that are directly for private patients (i.e. private beds in public hospitals). In both countries, a significant component of the cost of private health insurers is therefore for services provided to their membership in public hospital institutions. Third, salaried medical consultants who operate in public hospitals in both

\footnotetext{
${ }^{7}$ Armstrong (2010).

8 Nolan (2006).

${ }^{9}$ Connolly and Shelton Brown (2006).

${ }^{10}$ Armstrong et al. (2010).
} 
countries have historically been allowed to work in private hospitals in addition to their work in public hospital institutions.

\section{Overview of health insurance}

In both countries there are significant private health insurance markets. In Ireland a significant private health insurance market has developed since the establishment of the Voluntary Health Insurance Board in 1957. Currently, approximately 52 per cent of the population has chosen to purchase private health insurance polices equal to approximately 2.2 million persons. ${ }^{11}$ The benefit provided under such policies has historically been predominantly hospital-related. ${ }^{7}$ In Australia, at 44 per cent, ${ }^{12}$ a slightly lower proportion of the population purchase private health insurance but nonetheless its role is of equal and arguably greater importance given its broaderbased benefit package than in Ireland.

In summary, the following characteristics are relevant to consider for our analysis. First, both markets are voluntary-based markets in that individuals are free to choose whether to purchase health insurance, and if so from which insurance entity they purchase such insurance. Second, in both countries, private health insurance offers costs related to treatment that can be considered duplicative and supplementary to the public system outlined above.

Third, and most relevant to this analysis, both markets have adopted a number of regulatory measures to safeguard what is seen as the over-arching public policy objective for having private health insurance in their markets, namely risk-based solidarity. The explicit rationale for this has been to ensure that health insurance remains affordable for high-risk individuals and thus brings about some form of equity within the market. The mechanism under which this objective has been adopted in both countries has been through requiring insurers to engage in community-rated insurance under which, in simple terms, all individuals pay the same premium regardless of their risk profile.

To support community rating, a series of regulatory measures have been introduced in both countries including open enrolment regulations to ensure all-comers can take out insurance, lifetime cover to ensure individuals have access to insurance throughout their life and the introduction of minimum benefits related to treatment to force insurers to provide a minimum level of treatment for all individuals regardless of their risk profile. Such regulatory requirements are commonplace in insurance markets and have been documented extensively in the literature previously as a means of reducing adverse selection. ${ }^{13}$

In addition, in both countries, risk equalisation schemes have been established in legislation. Their aim is to provide a mechanism such that ex post differences in risk profiles between insurers (i.e. risk selection) that will undermine the solidarity objectives of the market are removed or, at least, negated.

\footnotetext{
${ }^{11}$ The Health Insurance Authority (2008).

12 Private Health Insurance Administration Council.

${ }^{13}$ Van de Ven and Ellis (2000).
} 


\section{Comparison of risk equalisation approaches in both of the countries}

\section{Historic role of risk equalisation}

In Australia, the current risk equalisation scheme is based upon legislation dating from the year 2007. ${ }^{14}$ Prior to this, a form of risk equalisation-based subsidies, historically referred to as "reinsurance", operated for many years. Its origins were based in the arrangement under which the Commonwealth Government of Australia reimbursed health funds for the relatively high claims costs associated with certain adverse risk groups. $^{15}$

In Ireland, risk equalisation has had a number of false starts in attempting to introduce transfers between insurers. Full details on this are presented elsewhere ${ }^{7}$ but even still (May 2010), owing to an Irish Supreme Court decision nullifying the regulations under which risk equalisation payments operate, ${ }^{7}$ no transfers have taken place between insurers using the risk equalisation mechanism that we model here. Instead, risk-related subsidies to older risk groups have taken place under the guise of the taxation system, though it is not referred to as risk equalisation, and has all the characteristics of a risk equalisation scheme. The Government has indicated that it is still committed to introducing a risk-equalisation scheme. ${ }^{16}$

The first risk equalisation regulations were introduced in $1996^{17}$ and made transfers between insurers using age, gender and a proxy measure of health status as the risk adjusters. These regulations were subsequently withdrawn in 1997 and a modified form of risk equalisation was reintroduced in 2003. ${ }^{18}$ The Supreme Court decision revoked these regulations and hence no formal risk equalisation scheme is in place at present. However, for the purposes of analysis, the fact that no transfers have taken place under the 2003 risk equalisation scheme, and that this scheme is no longer in place is irrelevant as we are comparing the stylised Irish system with that of the Australian system.

\section{Principal features of the risk equalisation systems}

We now outline some of the principal features of the schemes used for comparison purposes here from both of the countries. Fuller details are reported elsewhere. ${ }^{7,19}$ In summary, while both countries have a number of similarities in their schemes, they also have a number of important differences. These differences could, from a theoretical perspective at least, lead to significantly different incentives and outcomes for their respective markets. We start by identifying the similarities.

First, in both countries the manner in which the transfers are made (i.e. the modality) follows the method under which transfers are made between each insurer and a central fund based upon a comparison of their actual costs with their normative expenditures.

\footnotetext{
${ }^{14}$ Commonwealth Government of Australia, Private Health Insurance Act (2007).

${ }^{15}$ Collins (2008).

${ }^{16}$ Government of Ireland (2008).

${ }^{17}$ Government of Ireland (1996).

${ }^{18}$ Government of Ireland (2003).

${ }^{19}$ Connelly et al. (2010).
} 
In Ireland, normative expenditures are defined as the expected costs assuming each insurer had the age/gender (and potentially health status) risk profile of the insured population. In Australia, normative expenditures are defined, based upon each insurer having the expected costs per person of the insured population using the defined eligible benefits and thresholds (see below).

Second, in both countries transfers are made on a retrospective basis in that the normative expenditures of each insurer are calculated based upon historic costs and compared with historic actual expenditures during that period. The significance for this article of both countries having retrospective schemes and both using the same modality of transfers is that it makes it easy for a comparison of the effectiveness of each scheme to be undertaken. However, beyond this the differences as outlined below are quite material to the effectiveness of each scheme.

\section{Method of standardisation of risk profiles}

Direct and indirect standardisation methods are procedures to compare differences in health or health care expenditures between subgroups of the population after controlling for observable morbidity differences. ${ }^{20}$ In general, risk equalisation schemes based upon indirect standardisation do not remove incentives for risk selection. Conversely, risk equalisation schemes based on direct standardisation do remove incentives for risk selection, but at the cost of violating a neutrality condition, stating that insurers should receive the same premium subsidy for all members of the same risk group.

In Ireland, direct standardisation is used in that normative expenditures for each insurer are calculated based upon the insurer's own actual costs. In Australia, indirect standardisation applies as the normative expenditures are calculated based upon actual market costs. We consider this issue later in our conclusions from our results.

\section{Risk adjusters}

In Ireland, age and gender are the primary risk adjusters used. In addition, there is the possibility of making transfers of up to 50 per cent of the measured differences in risk profiles between insurers, based on the factors of age and gender, and on differences in health status profiles of insurers. In Australia, age is used as the principal risk adjuster with a high-cost claims pool being in place for expenditures incurred beyond a defined threshold that is currently set at $\mathrm{A} \$ 50,000 .^{21}$

The application of the age risk adjuster is also different between both countries. Ireland uses eight age bands $(0-17,18-29,30-39,40-49,50-59,60-69,70-79,80$ and over) broadly equivalent to ten-year age groups. In Australia, all persons under 55 years are grouped together, while smaller age bands are used beyond this age $(0-54,55-59$, 60-64, 65-69, 70-74, 75-79, 80-84 and 85 years and over). The relative age bands could have a significant impact on the effectiveness of any risk equalisation system given the variability of experience that could occur within each age group. For the

\footnotetext{
${ }^{20}$ Schokkaert and Van de Voorde (2008).

${ }^{21}$ Unless otherwise specified, all dollar amounts in this article are expressed in Australian dollars.
} 
purposes of this article, we have not considered the impact of the different age bands on the relative effectiveness of each system.

\section{Relationship between calculated required transfers and actual transfers}

In Ireland, equalisation transfers are made on the basis of 80 per cent of calculated risk solidarity payments, using the prescribed formula. In Australia, 100 per cent of the calculated transfers are made between insurers. The impact of the Irish framework is to reduce the effectiveness of the scheme in bringing about risk solidarity.

\section{Costs eligible for equalisation}

In Ireland, the acceptable costs for equalisation purposes are exclusively those paid for treatment received in hospital settings (day patient or inpatient). However, some costs are excluded from the equalisation process. Most, though not all of these, are for what is not arguably considered to be medical necessary treatments, for example some dental services.

In Australia, the nature of the costs acceptable for equalisation purposes is significantly more extensive, as it includes costs related to treatment provided in a hospital setting but also any costs incurred related to chronic disease management together with those relating to hospital substitute treatment (e.g. cancer treatment received at home). Furthermore, no limits are placed on the maximum level of benefits eligible for equalisation purposes (see below).

Thus, the incentive for insurers with adverse risk profiles to provide costs related to treatment that are more relevant to the medical needs of their insured persons is greater in Australia. This is because such an insurer will get compensated for any additional benefits in Australia, while in Ireland they may not necessarily get compensated, given the more extensive limitations on benefits eligible for equalisation.

\section{Method of equalisation}

In Ireland, for each insurer, the total normative cost of each insurer, calculated with the market profile of risk and using their actual costs, is compared with their actual aggregate cost. In Australia, for each insurer, the normative average cost for the market is compared with the insurers own actual average cost. A condition of the Irish scheme is that total normative expenditures for all insurers should equal total actual expenditures. This condition ensures that the scheme is self-financing. Thus, a zerosum adjustment is made to gross normative expenditures to ensure that this condition is met. The manner under which the zero-sum adjustment works theoretically, at least, is of significance in ensuring the contributing insurers are not financially discommoded..$^{22}$ Furthermore, it has implications for ensuring the efficiency objective of risk equalisation is met. No such budget constraint is explicitly required in Australia as the nature of indirect standardisation approach means self-financing is automatically attained.

\footnotetext{
${ }^{22}$ The zero-sum adjustment was changed in May 2007 from the original scheme.
} 


\section{Equalisation limits}

It is important to note that there are significant differences in terms of how a particular treatment might be handled under the Irish and Australian schemes. In Ireland, the benefit that gets included in the equalisation process is identical for all ages at prespecified maximum levels corresponding to required "solidarity" levels (i.e. luxury costs related to treatment are excluded). However, in Australia, the benefit that is admissible for equalisation varies by age band with no maximum levels beyond defined proportions (i.e. luxury costs related to treatment included). For example, 15 per cent of costs related to treatment paid for those aged 55-59 years are included in the risk equalisation calculation, while 70 per cent of all costs related to treatment for those 70-74 years are included.

\section{Membership for each insurer for purposes of calculating transfers}

Furthermore, in Ireland the calculation of risk equalisation transfers is undertaken effectively on a per person basis with the total number of insured lives being one of the metrics that will affect the contribution to or from the central fund for each insurer. In Australia, the appropriate measure of the size of the fund is based upon what is termed the number of "Single Equivalent Units" (SEU). This is a measure based on a prescribed formula which, in turn, is based on the number of hospital insurance policies that an insurer has registered. Each policy is given an SEU based on the number of adults and children registered on that policy. The significance of the differences in the measurement of the insured membership is difficult to judge, but it certainly will have some impact on the levels of transfers made.

\section{Frequency of calculation}

In both countries data is reported for each calendar quarter, though in Ireland returns are made on a six-monthly basis rather than quarterly, as is done in Australia.

\section{Use of health status as a risk adjuster}

\section{Ireland}

In Ireland, the 2003 risk equalisation system imposed a reserve power on the regulator to introduce a health status risk adjuster into the calculations of the transfers required between insurers and the central fund. The measure standardises health statuses between insurers in a given age and gender group. To do this, a proxy measure of health status is used based on what is termed the "cell value" of each insurer. This cell value is effectively the length of stay in a private bed (albeit within a public or private hospital).

To calculate the normative cost, a form of indirect standardisation applies. This means individual insurers retain their own cost per cell value but get the market average cell value per member and the market proportion of members in each age and gender group.

In order to limit the role of health status in the calculation, a maximum weight is given to the health status measure of 50 per cent, with the remaining weight being allocated to the age and gender normative calculation. Thus, under the Irish formula 
only a partial health status measure is used and even with that the measure of health status is rather crude.

\section{Australia}

Under the Australian formula there is no explicit health status variable used within the calculation. However, an implicit health status measure is introduced through the high cost claims pool. Under this arrangement, if an insured person has received costs related to treatment in excess of the defined threshold of A\$50,000 these excess costs related to treatment become part of acceptable cost for equalisation purposes regardless of the age of person.

\section{Model}

\section{Overview of model}

Our model uses a Monte Carlo type of simulation, as described by Hammersley and Handscomb, ${ }^{23,24}$ with repeated full replacement to evaluate the size of transfers under the different systems of risk equalisation that apply in both countries using repeated re-sampling of a base data set. The analysis is consistent with the boot-strapping technique outlined by Efron. ${ }^{25}$ The data set in question relates to the experience of a large Irish health insurer for the period July-October 2007 and which has approximately 1.54 million insured lives.

The simulation uses 1,000 separate iterations equivalent to allocating the members to one of five insurers of equal size 1,000 different times. Once members are allocated to an insurer, for each iteration, the transfers to that insurer are calculated using the defined Irish and Australian systems of equalisation (see below).

This exercise is analogous to randomly allocating a deck of 1.54 million cards to different insurers. In the case of Ireland, the calculation of the normative costs is undertaken using the age, gender and health status risk adjusters. In the case of Australia, the calculation of the normative costs is undertaken using the age and high cost claimants pool framework as currently applies. We believe that the number of iterations is sufficient to allow a meaningful and statistically robust analysis to be undertaken, given the large size of the data set.

The innovation in our model compared to other papers is two-fold. First, as indicated by Beck, ${ }^{26}$ previous studies have judged the effectiveness of risk equalisation schemes based upon their ability to predict health care expenditures in the future. ${ }^{27}$ Our study considers different risk equalisation schemes based upon their ability to discourage risk selection and encouraging efficient behaviour. Second, our model uses a very large data set, randomly allocates persons to different insurers and runs a large

\footnotetext{
${ }^{23}$ This is the classic reader on the theoretical aspects of Monte Carlo simulation.

${ }^{24}$ Hammersley and Handscomb (1964).

25 Efron (1979).

26 Beck (2006).

${ }^{27}$ Newhouse et al. (1989), van Berneveld et al. (2000), Holly et al. (2003).
} 
number of iterations to get statistically credible results. Previous studies have usually tended to use regression analysis to make such comparisons.

\section{The database used}

As indicated above, we used the database of a large Irish health insurer with about 1.54 million insured persons to allow us to undertake the simulation exercise. For the data set, the benefit package (and negotiated reimbursement rates) provided to all persons is different for each insurance product. ${ }^{28}$ Having multiple products does not invalidate the analysis as it merely reflects actual reality in both countries where product design is an important component of the competitive environment. The Appendix compares the nature of benefits provided for within the two countries. It should also be understood that because we are using the same data set for the calculations from the two countries this issue is less important for this particular study.

We consider that this provides credible results because of its size and the stable nature of the claims profile experienced by the insurer. A simulation exercise was undertaken to consider the reinsurance and capital requirements in micro-health insurance previously using a similar data set, and the justification for that analysis has been presented previously. ${ }^{29}$

It is important to emphasise that in using Irish data, we ignore the differences in health care settings, cost of treatments and incentives in Australia compared to that which prevails in Ireland. However, given the similarities in the health systems as outlined above, we do not consider that any differences are material to our analysis. Even if they were, the fact that both risk equalisation formulae use the same data makes this issue less important to the current analysis.

\section{Profile of membership and claims}

Before presenting our results, it is worthwhile to record the profile of membership and claims in our underlying data set. This is presented below. Table 1 shows the profile of membership using the Irish age bands.

For the Australian risk equalisation, the membership of 1.54 lives was equivalent to 994,160 single equivalent units. Furthermore, less than 0.2 per cent of members had claims that exceeded the high cost threshold as adopted in Australia.

\section{Assumptions}

In undertaking the analysis a number of assumptions are made.

First, five hypothetical insurers are assumed with an identical number of policies for each insurer. ${ }^{30}$ While making the number of policies identical is not the same as

\footnotetext{
${ }^{28}$ For the insurer, in question, there were approximately 20 products sold at the time of the simulation.

${ }^{29}$ Dror and Armstrong (2006).

${ }^{30}$ It was necessary to make the number of policies identical rather than members given the nature of the Australian formula that is based at the policy level.
} 
Table 1 Profile of membership using Irish age bands

\begin{tabular}{lr}
\hline Age band & Percentage \\
\hline $0-17$ & 23 \\
$18-29$ & 16 \\
$30-39$ & 16 \\
$40-49$ & 15 \\
$50-59$ & 13 \\
$60-69$ & 10 \\
$70-79$ & 5 \\
80 and over & 2 \\
Overall & 100 \\
\hline
\end{tabular}

Source: Underlying data set for members during base period (July-October 2007)

making the number of insured lives identical, the significance of the assumption is that it ensures that the size of the insurer is largely not relevant to the calculations. Otherwise, the relative size of each insurer could influence the level of transfers between each insurer.

While a different number of insurers could be used, it is felt that this number balances the need for a sufficient number of insurers with the need for ensuring that the volume of data and calculations do not become too cumbersome.

Second, it is assumed that one insurer has a known "worse" profile of risk relative to the other insurers. This was done by identifying policies where members on those policies had a historical adverse health status in the year prior to our base period and by allocating the majority of these policies to one insurer. The proxy measure used for health status was prior hospitalisation status for the previous year. ${ }^{31} \mathrm{We}$ allocated 80 per cent of these identified policies to one insurer with the balance being uniformly allocated to the other notional insurers. The percentage chosen reflected our need to ensure one insurer got the majority of adverse risks but not all of them.

This assumption allows us to consider the effectiveness of the different risk equalisation systems in discouraging risk selection. This is because an insurer who has the relatively worse risk profile would be expected to receive more in transfers than the other insurers.

Third, it is assumed that the A\$50,000 high cost claims threshold equates to $€ 20,882$ in Ireland using purchasing power parity. The applicable purchase power parity rate that is used is based upon the relativity of the published average costs per hospital night of the Australian health insurance regulator ${ }^{12}$ with the Irish private bed in public hospital average cost per hospital night. ${ }^{32}$

Fourth, the simulation does not control for any difference in risk profiles between insurers beyond that outlined in the second assumption above, as members on different

\footnotetext{
${ }^{31}$ The prior hospitalisation variable used is based on the measure used in Switzerland in their risk equalisation system. This says that if an individual has a hospital or nursing home stay of at least three days during the preceding year that is not related to a maternity stay, the individual is attributed to the class "with prior hospitalisation".

${ }^{32}$ Department of Health and Children (various years).
} 
health insurance policies are randomly allocated to each insurer. The method to allocate members to different insurers was based upon using the random number generator within the SAS computer package.

In addition to these explicit assumptions, it should be noted that while the cost profiles of the five insurers vary between each insurer, this is exclusively based upon their relative risk profile rather than any differences in the underling reimbursement levels. This is because the underlying data used in the simulation comes from this one Irish insurer that has standardised equalisation limits and reimbursement levels.

Furthermore, any differences in costs related to treatment eligible for equalisation are ignored between the countries and we therefore assume implicitly that the same package of costs related to treatment is eligible for equalisation in both countries.

\section{The risk equalisation schemes}

The different schemes of equalisation from each country are used to determine the transfers for each of the insurers in each country. The first system uses the Irish age, gender and health status measure with 100 per cent weighting. It also uses the zerosum adjustment that is part of the more recent Irish formula. As indicated above, this zero-adjustment means that the total transfers between insurers under risk equalisation equal zero. In other words, transfers to insurers are identically equal to transfers from insurers to the central fund. The second system adopts the Australian age-based pool together with the high cost pool calculation.

The Irish age- and gender-based system that only uses age and gender rather than health status is not reported. The reason for this is because our simulation exercise is based upon random sampling and is not stratified based on the age and gender profiles of those in the database, and thus expected total value of transfers is zero. This is because the random process would be expected to give the same age and gender profile for all insurers. While the results are not reported, it was shown that the mean aggregate transfer did not deviate from zero at a 99.5 per cent confidence level.

It is also the case that we do not adopt equalisation using the known current age gender profile of the Irish health insurance market. While this could be done, doing so would be of no real benefit to addressing the purpose of this article.

\section{Scenarios considered}

Two separate scenarios are considered. The first scenario considered is used to analyse the effectiveness of the two different methods in deterring risk selection. To answer this question, the benchmark measure was to determine the level of transfers to the insurer who had a known adverse profile of risk using the prior hospitalisation indicator of risk under each method. The method that gave a statistically higher level of transfer is considered to be the better method.

The second scenario analyses the effectiveness of the two methods in encouraging efficiency. To evaluate this, a comparison is made, under each method, of the change in the transfers to the insurer with the adverse profile of risk when the insurer becomes more efficient relative to the other insurers. To get a meaningful measure, this scenario considers the situation when the costs of this insurer are reduced by 50 per cent and all 
Table 2 Transfers to the insurer with the adverse risk profile $(n=1,000)$

\begin{tabular}{lcr}
\hline Statistic & Ireland & Australia \\
\hline Mean transfer & $€ 61,018,000$ & $€ 32,283,000$ \\
Standard deviation & $€ 927,000$ & $€ 350,900$ \\
Co-efficient of variation & $1.5 \%$ & $1.1 \%$ \\
\hline
\end{tabular}

other insurers have the same costs. In fact, the impact of this efficiency is scale invariant to the change in costs for this insurer. In other words, reducing costs will have the same impact (i.e. a reduction, an increase or no change) in its relative efficiency regardless of the size of the reduction. Such a reduction in costs for this insurer could arise for many reasons, including the fact that the insurer has negotiated better reimbursement arrangements with medical providers, moved patients to more appropriate and cheaper medical settings and/or shifted the demand of its members to less costly treatment as a direct result of disease management programmes.

\section{Results}

\section{Effectiveness in deterring risk selection}

The transfers to the adverse insurer are summarised in Table 2 under the first scenario.

It is clear from the results presented in Table 2 that the transfers are significantly greater using the Irish method rather than the Australian method of risk equalisation. Given that this insurer has an adverse risk profile, it would then seem to imply that the Irish method is better at deterring risk selection in that it penalises insurers who have a favourable risk profile more than the Australian method of risk equalisation.

However, while this may be the case, this does not mean that the Irish method is optimal at achieving risk solidarity as it may be the case that the transfers under the Irish method are excessive compared to the actual difference in risk profiles between insurers. We cannot be sure of whether this is the case or not as we do not know what is the optimal transfer to the insurer with the adverse risk profile. This is a further research question that is not fully addressed in this article.

Nonetheless, from the iterations of the Irish data, it is clear that the transfers are such that following risk equalisation the average claims cost per person for each contributing insurer are effectively identical and differ from of the insurer with the adverse profile only as a result of the fact that transfers are only 80 per cent of the required levels under the Irish risk equalisation system. This would support the idea that the Irish system does not over-compensate and, in fact, under-compensates insurers even for differences in health status measurable using the cell value framework. ${ }^{33}$

\footnotetext{
${ }^{33}$ In fact, the under-compensation may be greater as in our simulations the claims costs per cell value are largely identical for each insurer in each age and gender cell (given that they are derived from the same insurer). If a contributing insurer could target individuals, who have a lower average cost per cell value within a given age band and gender cell, they would get to keep this advantage. In reality there is some evidence that this happens (Health Insurance Authority Staff Reports, various years). This supports the
} 
Table 3 Impact of reduction in costs for insurer with adverse profile

\begin{tabular}{lcc}
\hline Statistic & Ireland (\%) & Australia (\%) \\
\hline $\begin{array}{l}\text { Mean transfer as proportion of old transfer } \\
\text { for each iteration }\end{array}$ & 100 & 39 \\
\begin{tabular}{l} 
Reduction in contributions \\
\hline
\end{tabular} & 0 & 61 \\
\hline
\end{tabular}

While the size of the transfer under the Irish system of risk equalisation is significantly better on average ${ }^{34}$ than that under the Australian system of risk equalisation, it comes at a cost. The cost is that the variability of the size of the transfer is higher as measured by the coefficient of variation of the transfer to the insurer with the adverse risk profile. The implication of this for individual insurers is that there is an increased range in the size of the transfers they would receive under the Irish system, for a given risk profile, as compared to that under the Australian system. However, this variability is very small in comparison to the benefit in terms of getting a higher transfer under the Irish system.

In addition, it is quite possible that the effectiveness of each method in deterring risk selection may be a function of both the size of individual insurers and the risk imbalance between each insurer. To be categorical on whether this is the case or not would be difficult, as having insurers of different sizes would mean other matters would become material to the analysis. However, from our review of a couple of alternate non-symmetrical distributions scheme sizes, this is not the case.

\section{Effectiveness in encouraging efficiencies}

The results of the second scenario where the costs of the insurer with the adverse risk profile are presented in Table 3. The table shows that, under the Irish method of equalisation, the transfers do not diminish if a recipient insurer (i.e. an insurer with an adverse profile of risk) reduces its costs. Conversely, the required contribution from contributing insurers will not decrease. This could be considered to be an efficient outcome as recipient insurers do not receive a lower transfer as a result of reducing their claims cost per person (i.e. becoming more efficient), and therefore suffer no penalty for this occurring. A similar result can be shown for contributing insurers insofar as that if they reduce their claims costs per person their contributions will decrease by the same percentage.

The results under the Irish system of risk equalisation arise directly from the zerosum adjustment in the calculation formula. The prescribed formula is such that all transfers are based upon actual own costs of "contributing" insurers rather than the market average. This is tantamount to direct standardisation. Thus, if a recipient

view that the Irish health status method is likely to under-compensate insurers with adverse risk profiles. As indicated above, a full discussion of this is outside of scope of the current article.

${ }^{34}$ In fact, the Irish method generated higher transfers for all 1,000 iterations. 
insurer manages to reduce their costs, they keep all the advantages of so doing, that is, the scheme in Ireland is 100 per cent efficient.

If other methods were used to allow for the zero-sum adjustment, the 100 per cent efficiency level in Ireland would not be met. However, the answer would be close to 100 per cent. Under some methods insurers would be over-compensated for becoming more efficient, while in other cases insurers would be under-compensated. The exact percentage would be determined based on the relative cost distributions and sizes of schemes.

In the case of the Australian system, a 50 per cent reduction in costs for the insurer with the adverse risk profile ${ }^{35}$ means that its compensation for having the adverse risk profile is reduced by 61 per cent. In other words, if a recipient insurer becomes more efficient, they become relatively worse off as their payment diminishes by a higher percentage. Thus, the results suggest that there is no incentive for the insurer to become more efficient. Of course, if the extent of the payment is very low, this loss may be compensated by a higher absolute efficiency gain. ${ }^{36}$

\section{Conclusions and lessons for risk equalisation design/analysis}

The analysis has provided a framework for the comparison of retrospective risk equalisation systems. It has shown that it is not easy to compare outcomes even for similar modalities of risk equalisation as in Ireland and Australia.

Using our framework, it was shown that the Irish age, gender and health status mechanism appears to be both better in terms of discouraging risk selection and allowing insurers to retain efficiency gains compared to the Australian system. This conclusion has a general validity assuming that the proportions of benefits eligible for equalisation under the Australian risk equalisation system do not change. Thus, the results would hold if Australian data were to be used instead of Irish data. ${ }^{37}$

Despite the validity of this result, further work is required to analyse the impact of changing the structure of the age bands, the proportions of costs related to treatment within each age band that are equalised in Australia, and the impact of the high claim cost HCCP threshold. This would determine the extent of how superior the Irish formula is using a range of alternative scenarios.

The analysis presented ignores any detailed discussion of the predictive abilities of each of the systems except to the extent that they discourage risk selection and promote efficiency. However, analysing the predictability power of each scheme based on consideration of its ability to project future health expenditures is arguably of less relevance to a comparison of retrospective schemes of risk equalisation.

\footnotetext{
35 This is based on the assumed size of each of the insurers.

${ }^{36}$ Consider the situation where costs per capita go down from 1,000 to 500 as a result of an efficiency gain, that is, a saving of 50 per cent. If the initial risk equalisation transfer was only 200 per capita, a 61 per cent reduction would only mean a fall by 122 . Therefore, despite the reduction being proportionately higher, the overall effect of becoming more efficient is positive.

${ }^{37}$ This can be proved mathematically but is beyond the scope of this article.
} 
536

The Irish direct standardisation approach, while it can remove the risk selection incentives and is relatively better than the corresponding indirect standardisation approach used in Australia, comes at the cost that, depending upon whether you are a contributing or recipient insurer, your subsidies in a given age group are be different. ${ }^{20}$ Nonetheless, the direct approach does encourage efficiency in that recipient insurers are not penalised for becoming more efficient and contributing insurers get to retain all of their efficiency gains. Under this Australian system this is not the case. This suggests that direct standardisation methods should be considered more often when considering the design of a risk equalisation mechanism.

In conclusion, our analysis could easily be extended so that a comparison could be made of the performance of the different risk equalisation systems that apply in other countries that have broadly similar forms of risk equalisation. In particular, the experience of Switzerland and South Africa could easily be analysed to gain further insight into the optimal risk equalisation system.

\section{References}

Armstrong, J. (2008) Subsidies in private health insurance: The case of Ireland, paper presented to the European Conference on Health Economics, Rome, Italy.

Armstrong, J. (2010) 'Risk equalisation: The case of Ireland', Health Policy, (forthcoming).

Armstrong, J., Paolucci, F., McLeod, H. and van de Ven, W.P.P.M. (2010) 'Risk equalisation in voluntary health insurance markets in three countries', Health Policy, (forthcoming).

Beck, K (2006) 'Risk Adjustment in Health Insurance: Effectiveness and Sustainability', CSS Institute for Empirical Health Economics, Working Paper 2006.01 from http://www.css.ch.

Collins, P. (2008) An historical perspective on risk-equalisation for private health insurance in Australia, presentation to ACERH Research Forum, 10 June 2008.

Commonwealth Government of Australia (2007) 'Private Health Insurance Act 2007', (Australia), from www.comlaw.gov.au.

Connelly, L., Paolucci, F., Butler, J.R.G. and Collins, P. (2010) 'Risk equalisation and voluntary health insurance markets: The case of Australia', Health Policy, (Forthcoming).

Connolly, L.B. and Shelton Brown III, H. (2006) 'Lifetime subsidies in Australian private health insurance markets with community rating', The Geneva Papers on Risk and Insurance-Issues and Practice 31(4): $705-719$.

Department of Health and Children (various years), from http://www.dohc.ie.

Dror, D.M. and Armstrong, J. (2006) 'Do micro health insurance units need capital or reinsurance? A simulated exercise to examine different alternatives', The Geneva Papers on Risk and Insurance-Issues and Practice 31(4): 739-761.

Efron, B. (1979) 'Bootstrap method: Another look at the jackknife', Annals of Statistics 7(1): 1-26.

Enthoven, A. (1978) 'Consumer-choice health plan', The New England Journal of Medicine 298(12): 650-658, and (13): 709-720.

Hammersley, J.M. and Handscomb, D.C. (1964) Monte Carlo Methods, New York: John Wiley \& Sons.

Health Insurance Authority Staff Reports (various years), from http://www.hia.ie.

Holly, A., Gardiol, L., Eggli, Y., Yalcin, T. and Ribeiro, T. (2003) Health-based Risk Adjustment in Switzerland: An Exploration Using Medical Information from Prior Hospitalisation, Mimeo Institut d'economie et management de la santé: Lausanne.

Government of Ireland (1996) 'Regulations', from http://www.gov.ie.

Government of Ireland (2003) 'Health Insurance Regulations', from http://www.gov.ie.

Government of Ireland (2008) 'Press Statement of Minister for Health and Children, Ms. Mary Harney', from http://www.dohc.ie.

Newhouse, J., Manning, W., Keeler, E. and Sloss, E. (1989) 'Adjusting capitation rates using objective health measures and prior utilization', Health Care Financing Review 10(3): 41-54. 
Nolan, B. (2006) 'The interaction of public and private health insurance: Ireland as a case study', The Geneva Papers on Risk and Insurance - Issues and Practice 31(4): 633-649.

Paolucci, F., van de Ven, P.M.M. and den Exter, A. (2007) 'Solidarity in competitive health insurance markets: Analysing the relevant EC legal framework', Health Economics Policy and Law 2(2): 173-192.

Private Health Insurance Administration Council (2007) from http://www.phiac.gov.au.

Schokkaert, E. and Van de Voorde, C. (2008) Direct Versus Indirect Standardization in Risk Adjustment, paper presented to Risk Adjustment Meeting, Journal of Health Economics 28(2): 361-379.

Schut, F.T. (1995) Competition in the Dutch health care sector, Rotterdam, Erasmus Universität. Rotterdam. Dissertation.

The Health Insurance Authority (2008) Annual Report, from http://www.hia.ie.

van Berneveld, E., Lamers, L., van Vliet, R. and van de Ven, W.P. (2000) 'Ignoring small predictable profits and losses: A new approach for measuring incentives for cream skimming', Health Care Management Science 3(2): 131-140.

van Barneveld, E.M., Lamers, L.M., van Vliet, R.C. and van de Ven, W.P. (2001) 'Risk sharing as a supplement to imperfect capitation: A tradeoff between selection and efficiency', Journal of health economics 20(2): 147-168.

Van de Ven, P.M.M., Beck, K., Buchner, F., Cherichovsky, D., Gardiol, LV. and Holly, A. (2003) 'Risk adjustment and risk selection on the sickness fund insurance market in five European countries', Health Policy 65: 75-98.

Van de Ven, P.M.M., Beck, K., Van de Voorde, C., Wasem, J. and Zmora, I. (2007) 'Risk adjustment and risk selection in Europe: 6 years later', Health Policy 83: 162-179.

Van de Ven, P.M.M and Ellis, R.P. (2000) 'Risk adjustment in competitive health plans', in A.J. Culyer and J.P. Newhouse (eds.) Handbook of Health Economics, Amsterdam: Elsevier, pp. 755-845, (Chapter 14).

\section{About the Authors}

John Armstrong is an actuary and health economist. He is an associate lecturer of the Institute of Public Administration and works with the Voluntary Health Insurance Board in Dublin, Ireland. He has advised many governments throughout the world on health financing issues.

Francesco Paolucci is Research Fellow at the Australian Centre for Economic Research on Health in Canberra. Prior to taking up his current appointment, he has held appointments as a visiting researcher/lecturer in the University of Bologna, University of Oslo and at the Erasmus University Rotterdam. 


\section{Appendix}

See Table A1.

Table A1 Coverage of the benefit packages under the risk/claim equalisation arrangements

\begin{tabular}{lll}
\hline & Australia & Ireland \\
\hline Physicians services-non consultants & No & No \\
Hospital care & Yes & Yes \\
Medical specialist for hospital care & Yes & Yes \\
Prescription drugs & Yes & No \\
Physiotherapy & Yes & In some plans \\
Dental care & No & Very limited \\
Home health care & Yes but limited & Very limited \\
Nursing home care & No & Limited, only as convalescent \\
Psychiatric care & No & Yes \\
\hline
\end{tabular}

Amended from Armstrong et al (2010).

Glossary (amended from Van de Ven et al. (2003) and Armstrong et al. (2010)

Direct standardisation: direct standardisation method transforms expenditures by applying a standard needs profile to the actual expenditure profile of the group.

Efficiency: throughout the article we refer to dynamic efficiency, which is defined as quality-improving and cost-reducing innovations in the organisation and delivery of care.

Indirect standardisation: indirect standardisation method transforms expenditures by applying an exogenously given standard level of expenditure to the actual population structure of the group.

Market instability: Instability in the market arising directly from the risk selection actions of consumers or insurers.

Selection: Actions (except premium differentiations) by insurers and consumers to exploit heterogeneity in risk profiles between consumers, and therefore maximise their profits. Where imperfect premium differentiation or imperfect equalisation is in place the incentive to engage in risk selection and break pooling arrangements is great.

Solidarity: Solidarity is cross-subsidies between individuals. Two types of solidarity exist - risk solidarity from low-risk to high-risk groups and/or income solidarity from high- to low-income groups.

Disclaimer: All views expressed in the article are personal and do not reflect the views of the authors' institutions. 